\title{
Identification of Epicatechin Gallate and Other Phytochemicals in Methanol Extract of Fresh and Dried Star-Fruits (Averrhoa carambola Linn.) for Treatment of Type 2 Diabetes Mellitus
}

\author{
Yustika Sari ${ }^{1}$, Dono Indarto ${ }^{2 *}$, Brian Wasita $^{3}$ \\ \{yustikasari.78@student.uns.ac.id ${ }^{1}$, dono@staff.uns.ac.id ${ }^{2}$, brianwasita@yahoo.com ${ }^{3}$ \}

\begin{abstract}
Postgraduate Student of Clinical Nutrition, Universitas Sebelas Maret, Surakarta, Indonesia ${ }^{1}$, Postgraduate Program of Nutrition Sciences, Universitas Sebelas Maret, Surakarta, Indonesia ${ }^{2,3}$, Department of Physiology, Faculty of Medicine, Universitas Sebelas Maret, Surakarta, Indonesia ${ }^{2}$, Biomedical Laboratory, Faculty of Medicine, Universitas Sebelas Maret, Surakarta, Indonesia ${ }^{2}$, Department of Anatomy Pathology, Faculty of Medicine, Universitas Sebelas Maret, Surakarta ${ }^{3}$, Corresponding author*
\end{abstract}

\begin{abstract}
From an in-silico study, Averrhoa carambola L. (star fruit) contains epicatechin gallate (ECG), which has a similar effect to Sodium-glucose co transporter 2 (SGLT2) inhibitor. This study aimed to identify ECG and other phytochemicals in methanol extracts of fresh and dried star fruits. Ripened star-fruits (RSFs) were divided into two parts: directly extracted using methanol, while the other was dried and were then extracted using methanol. ECG and phytochemicals were identified using GC-MS, LC-MS and spectrophotometer. The yield of fresh RSFs extract was approximately double than that of dried RSFs extract. 4H-Pyran-4-one,2,3-dihydro-3,5-dihydroxy-6-methyl- was the highest phytochemicals in fresh RSFs extract whereas dried RSFs extract had glycerine. However, extract of dried RSFs had higher ECG levels than that of fresh RSFs $(p=0.002)$. In conclusion, methanol extract of dried RSFs has higher ECG levels and different phytochemicals than fresh RSFs, which potentially become a diabetes herbal drug for an SGLT2 inhibitor.
\end{abstract}

Keywords: Sodium-Glucose Co-Transporter 2 inhibitor, Star Fruits Extract, Epicatechin Gallate, Type 2 Diabetes Mellitus

\section{Introduction}

The prevalence of type 2 diabetes mellitus (T2DM) has been rising in this decade, which increases the number from $4.7 \%$ in 1980 to $8.5 \%$ in 2014 [1]. Three in four people with diabetes are between the ages of 20 and 64 years old [2]. Therefore, younger adults with diabetes mellitus need oral hypoglycemic drugs to improve insulin secretion, reduce insulin resistance, and increase glucose uptake to lower blood glucose levels [3].

Sodium-glucose co-transporter 2 inhibitor (SGLT2i) is a glucose-lowering drug that inhibiting glucose and sodium reabsorption in the kidneys, thus resulting in glucosuria (calorie loss). Consequently, the effect includes reductions in blood glucose levels and decreases in body weight and adiposity, potentially addressing the caloric excess [4-6]. Dapagliflozin is the SGLT2 inhibitor has the most clinical data to date, and other SGLT2 inhibitor are actively being 
developed [7]. However, long-term use of this medicine might cause genital infections, ketoacidosis and dehydration $[8,9]$. As a result of these adverse effects, we are exploring for natural substances that work similarly to SGLT2i.

SGLT2 was validated with dapagliflozin with a binding affinity of $9.0 \mathrm{kcal} / \mathrm{mol}$. The standard interacted with SGLT2 at the residues Asn ${ }^{75}$, Gly ${ }^{79}$ and His ${ }^{80}$. From 422 samples, 29 had lower binding affinities than dapagliflozin, but only ECG had similar binding interaction with dapagliflozin at all three residues. ECG in Averrhoa carambola was predicted to be a more potent SGLT2i than dapagliflozin based on computational analysis [10].

Averrhoa carambola $L$. (sweet star fruit) has high primary and secondary metabolites such as polyphenols that can modulate the gut microbiota [11]. From an in silico study, Averrhoa carambola L. (star fruit) contains a secondary metabolite (ECG) that can interacts with the SGLT2 protein, as same dapagliflozin as at $\mathrm{Asn}^{75}, \mathrm{Gly}^{79}$, and $\mathrm{His}^{80}[10]$. Methanol was the best solvent for the extraction of ECG [12]. Therefore, we used star fruit extracted with methanol. So far, there has not been reported the content of ECG in star fruit. Thus this study aimed to identify ECG and other phytochemicals in methanol extracts of fresh and dried star fruits.

\section{Research Methods}

\subsection{Extraction of Star Fruits}

Ripened star-fruits (RSFs) in this study were purchased from a farmer at Demak, Central Java. Before extracted, RSFs were washed carefully with tap water and divided randomly into fresh and dry parts. Both parts were chopped into small slices $( \pm 0.5 \mathrm{~cm})$, but only the dry part was oven-dried at $40^{\circ} \mathrm{C}$ for 36 hours. Then fresh and dry RSFs were made simplicia by using a disintegrator for $3 \mathrm{~min}$. Simplicia of fresh RSFs was extracted using an existing method with some modifications [12-14]. A total amount of fresh RSFs Simplicia was mixed with chilled methanol for 5 min with a ratio of 1:2. After centrifugation, the suspension was filtered using $0.45 \mu \mathrm{m}$ membrane paper, and the supernatant was dried using a vacuum evaporator at $45^{\circ} \mathrm{C}$ for 4 hours and a blower evaporator for 24 hours. Meanwhile, Simplicia of dry RSFs was extracted using the maceration method with methanol solvent. This method was adopted from Kallithraka et al. (1995) with slight modification. One part of Simplicia was dissolved in three regions of methanol solvent [12]. The dissolved solution was filtered using $0.45 \mu \mathrm{m}$ membrane paper to get the supernatant. To obtain a solid extract, the supernatant was dried as same as the fresh RSFs extract.

\subsection{Identification of ECG Compound}

The standard ECG compound was obtained from Sigma-Aldrich USA. For ECG analysis using GC-MS, fresh and dry RSFs extracts were diluted in methanol to reach $100 \mathrm{ppm}$ final concentration. One $\mu 1$ diluted sample was injected into a ZB-5MS (30 $\mathrm{m}$ x $0.25 \mathrm{~mm} \times 0.25 \mu \mathrm{m})$ column (Phenomenex ${ }^{\circledR}$, Torrance, CA, USA), linked to a Trace IQS LT mass detector (San José, CA, USA) (GC-MS) and a Thermo Scientific AI 1310 automatic injector (San José, CA, USA) at $300{ }^{\circ} \mathrm{C}$. A flow rate of chemical analysis was set up at $1 \mathrm{ml} / \mathrm{min}$. The spectrum of chemical compounds in the samples was identified using the standard chemical compounds in the NIST library. 
Another method used to identify ECG compounds in the fresh and dry RSFs extracts was the LC-MS with a C18 reverse-phase BioSuite ${ }^{\mathrm{TM}}$ column $(4.6$ x $150 \mathrm{~mm}$, Waters Corporation). The mobile phase was made up of (A) $0.5 \%$ formic acid in water and (B) acetonitrile was used to separate ECG from other chemical compounds, and a $20 \mu \mathrm{L}$ sample was injected into the column with $0.6 \mathrm{~mL} / \mathrm{min}$ flow rate. The following was the concentration gradient of mobile phase: 0-5 $\min , 90: 10$ (A:B); 5-7 $\mathrm{min}, 90: 10$ to $86: 14$ (linear gradient); 7-17 min at 86:14; 17 $19 \mathrm{~min}, 86: 14$ to $75: 25$ (linear gradient); 19-24 min at 75:25; 24-25 $\mathrm{min}, 75: 25$ to 10:90 (linear gradient); 25-31 min held at 10:90; 31-32 min, 10:90 to 90:10, 32-40 min at 90:10 [15]. Data of peak and retention time of fresh and dry RSFs extracts were compared with the Waters Masslynx 4.1 library data.

\subsection{Quantification of ECG Compound}

A UV-visible spectrophotometer was used to determine ECG compounds in the fresh and dry RSFs extracts compared to the diluted standard ECG from 0 to $20 \mathrm{mg} / \mathrm{L}$. The standard ECG and RSFs extracts were diluted with methanol to make various concentrations. Three different samples of fresh and dry RSFs quotes were measured with a spectrophotometer at $277 \mathrm{~nm}$. A regression linear was drawn to calculate ECG concentration in the new and dry RSFs extracts.

\subsection{Statistical Analysis}

Data of ECG concentrations in fresh and dry RSFs extracts were provided as mean \pm standard deviation (S.D.) and statistically analyzed with the independent t-test. A statistical difference used $P$-value $<0.05$.

\section{Results and Discussion}

\subsection{Fresh RSFs Yielded More Extract than Dried RSFs}

Table 1. Rendement of star fruit extracts.

\begin{tabular}{lrrlrrr}
\hline & RSFs $(\mathrm{g})$ & \multicolumn{1}{c}{ Simplicia $(\mathrm{g})$} & Solvent Ratio & Time $(\mathrm{min})$ & Extract $(\mathrm{g})$ & Yield $(\%)$ \\
\hline Fresh & 44.44 & - & $1 \mathrm{~g}: 2 \mathrm{ml}$ & 20 & 12.70 & 28.58 \\
Dried & $6,000.00$ & $2,357.77$ & $1 \mathrm{~g}: 3.33 \mathrm{ml}$ & 3 & 801.64 & 13.36 \\
\hline
\end{tabular}

Table 1 summarized the extract yield of fresh and dried RSFs. Fresh RSFs yielded 2.14 times higher extracts than dried RSFs because high temperatures may lead polymers (e.g., carbohydrates and proteins) to degrade and labile compounds (e.g., glucosinolates or lipids) to oxidize [16]. During the drying process, the proportion of phenolic compounds in dried RSFs also reduced because it could be attributed to the degradation of heat-sensitive phenolic compounds [13].

The research finding in our study is different from a previous study in that freeze-dried RSFs with chloroform-methanol combination yielded a 7\% fraction [17]. Pothasak et al. (2020) found that RSFs extraction using a freeze-drying technique produced 5.33\% extract, lower than the yield of our RSFs section [18]. Another study also reported that extraction using an air-dried method yielded $14.86 \%$ extracts, but Chinese researchers used star fruit leaves [19]. 


\subsection{Identification of ECG Compound}

Based on GC-MS's chemical analysis and library data, we found different peaks and retention times (R.T.) between the standard ECG and methanol extracts of fresh and dried RSFs (Figure 1a-c). From Figure 1a, the highest relative abundance of chemical compounds in the standard ECG is Dodecanoic acid methyl ester with 13.73 min R.T. In contrast, the most elevated close lot of chemical compounds fresh and dried methanol extracts RSFs have different R.T. (Figure $1 \mathrm{~b} \& \mathrm{c})$. In the methanol extract of fresh RSFs, 2,3-Butanediol, [S-(R*, $\left.\left.\mathrm{R}^{*}\right)\right]$ - was detected at 4.18 min R.T. and 4H-Pyran-4-one, 2,3-dihydro-3,5-dihydroxy-6-methyl- had 10.12 min R.T., which were more dominant than other chemical compounds. Moreover, the three highest relative abundance of chemical compounds was observed in methanol extract of dried RSFs were 2,3-Butanediol, [S-(R*, $\left.\mathrm{R}^{*}\right)$ ]- with 4.26 RT, 4H - Pyran- 4 - one, 2, 3 - dihydro - 3, 5 dihydroxy -6 - methyl - with $10.12 \mathrm{RT}$ and 5 -Hydroxymethylfurfural with 11.14 mins R.T.s. Unfortunately, we did not find any ECG compound among the three chromatograms.

Comparing to previous studies, the results of our RSFs extracts' GC-MS analysis differed.. According to a research study conducted in Malaysia, Tridecane, 4-methyl- compound has the highest peak with 13.75 min R.T. At the same time, GCMS analysis of RSFs extracts from Bogor Indonesian, Egypt, and India indicated that the highest peak was Nerylacetone at 4.43 min R.T., Methyl caproate at 7 min R.T. and 9-Octadecenoic acid (Z)-, methyl ester at 22 min R.T. respectively [20,21]. Despite limitations of GC-MS analysis in terms of the mass range and metabolites polarity, using the derivatization technique has expanded the range of separable and detectable chemical compounds in high-throughput profiling research. In addition, several artifacts caused by the derivatization reagent were observed in the GC-MS chromatograms. Therefore, N-methyl-N-(trimethylsilyl)-trifluoroacetamide (MSTFA) or N,O-bis(trimethylsilyl) trifluoroacetamide (BSTFA) is often used for artefacts removal during derivatization [22].

(a)

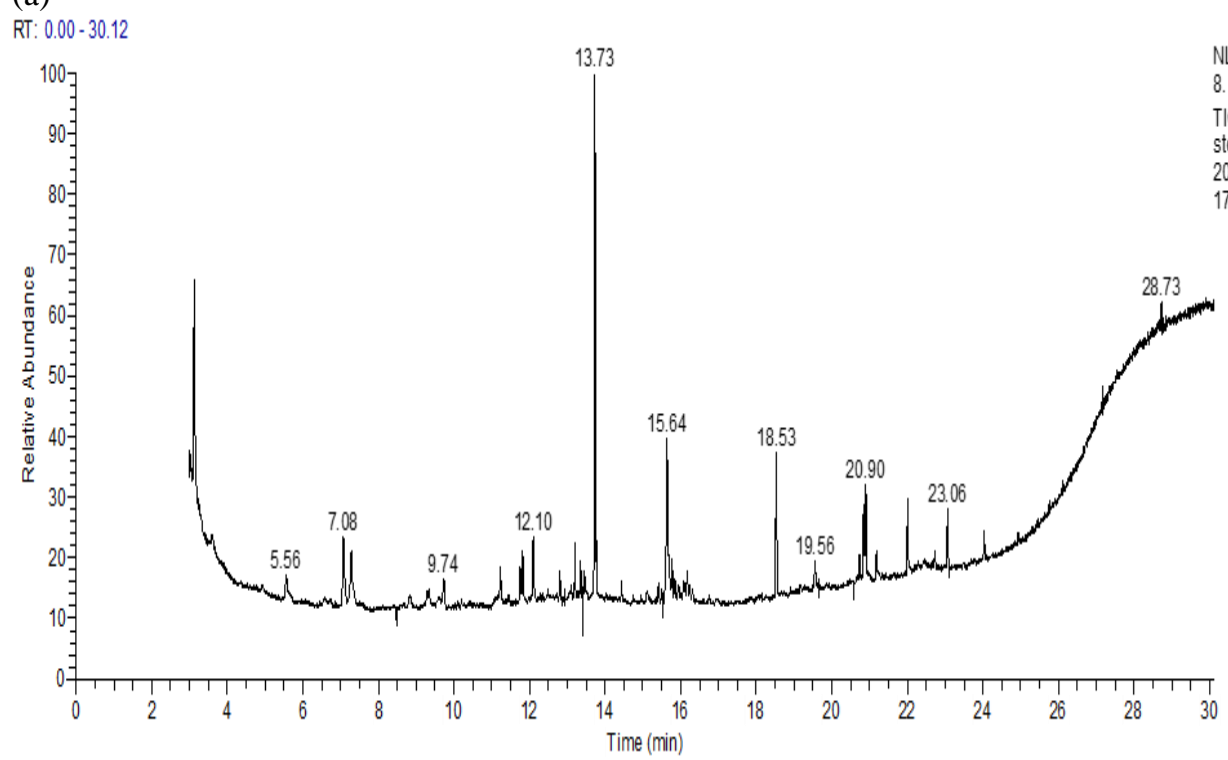

(b)

8 .10E

TIC MS

stdkatekin

17 


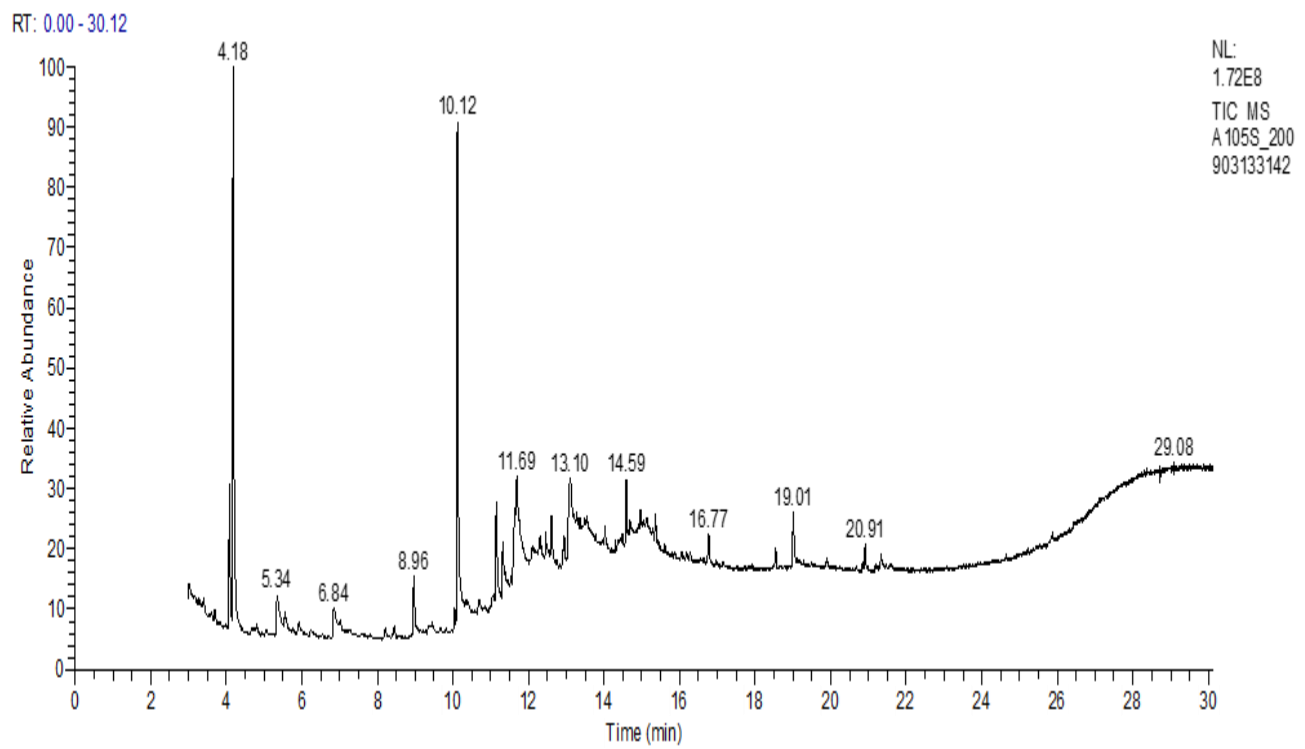

(c)

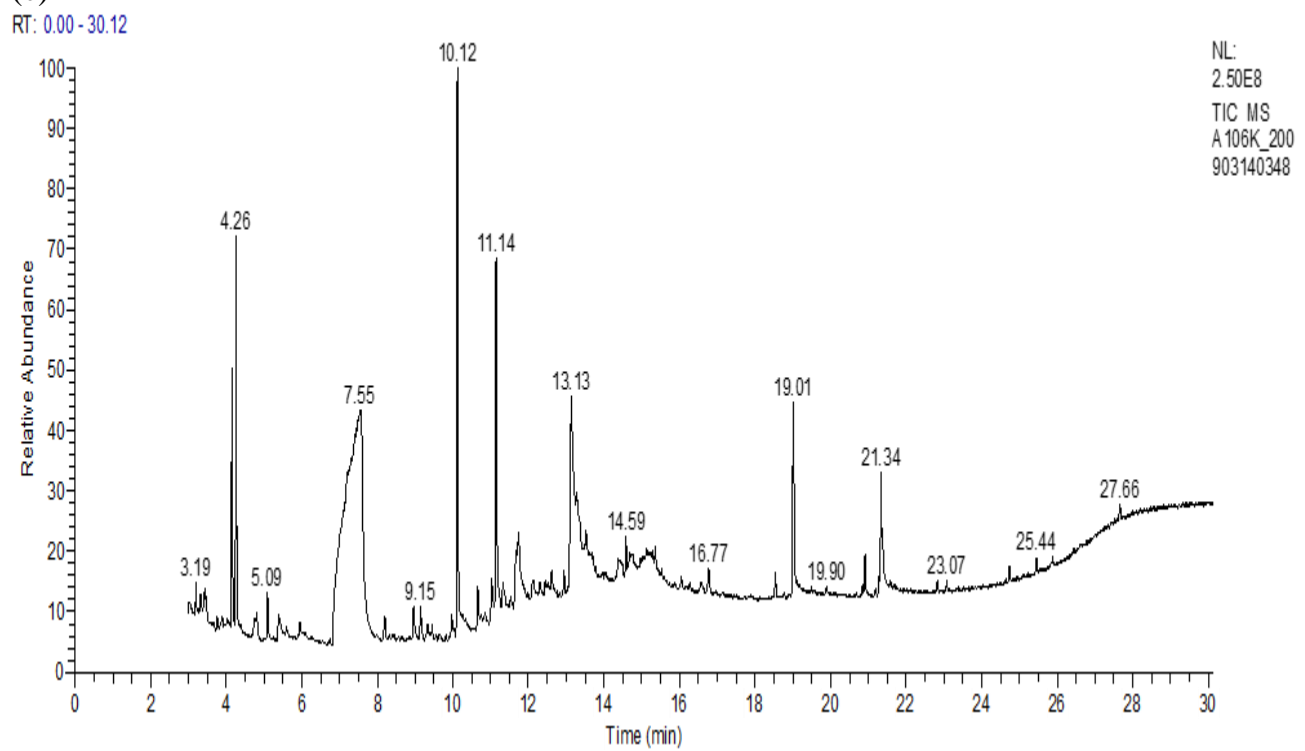

Fig. 1. GC-MS chromatogram results of methanol extract derived from ECG high purity (a), fresh (b), and dried RSFs (c).

To identify ECG compounds in both RSFs extracts, we tried to analyze them using the LCMS equipment (Figure 2a-c). The three highest peaks of ECG standard were observed at 293.66, 441.84, and $442.05 \mathrm{~m} / \mathrm{z}$, while fresh and dried RSFs extracts had the same peaks at $293.60 \mathrm{~m} / \mathrm{z}$. The other highest peak in fresh rSFs extracts were 311.68 and $237.36 \mathrm{~m} / \mathrm{z}$, whereas the dried 
RSFs extracts had 293.73 and $294.69 \mathrm{~m} / \mathrm{z}$. based on the library of MassBank of North America (MoNA) [NP C2 126_p4_G08_POS iTree 06], (-)-epicatechin 3-O-gallate has 447.0864 molecule weight and two fragmented ions [327.0553 and $295.0933 \mathrm{~m} / \mathrm{z}$ ] [23]. In previous reports, parent ion with $441 \mathrm{~m} / \mathrm{z}$ corresponds to monomeric epicatechin gallate, identified as (-)-epicatechin gallate by direct comparison to ${ }^{1} \mathrm{H}$ and ${ }^{13} \mathrm{C}$ NMR spectral data [24]. However, the parent ion with $441 \mathrm{~m} / \mathrm{z}$ was low and was not detected in Figure $2 \mathrm{~b}$-c.

(a)

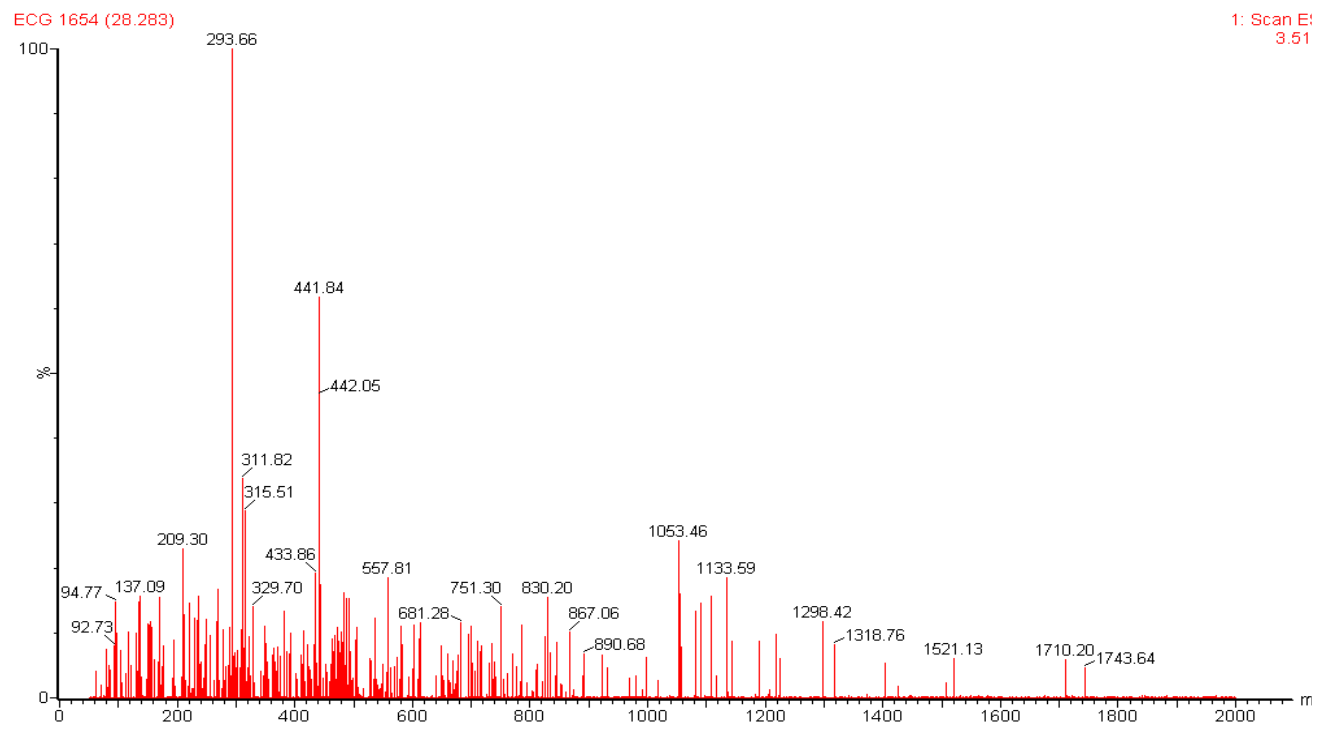

(b)

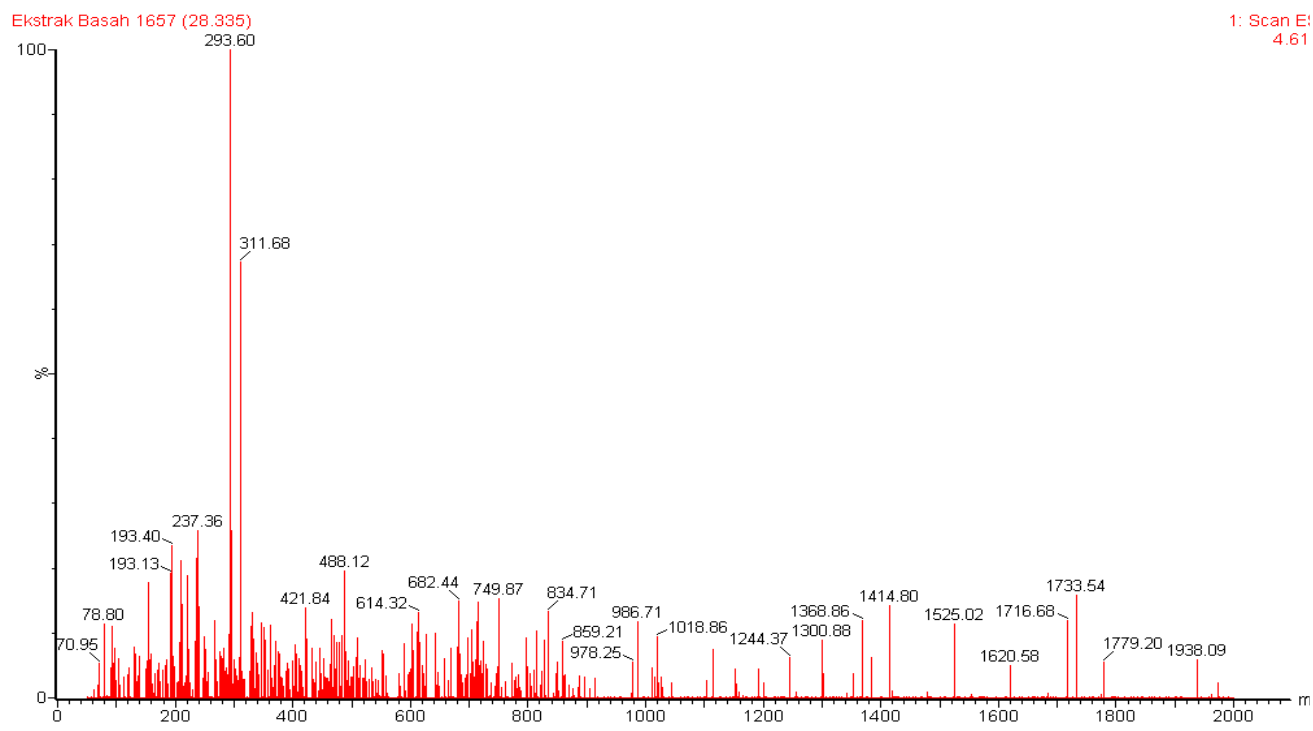

(c) 


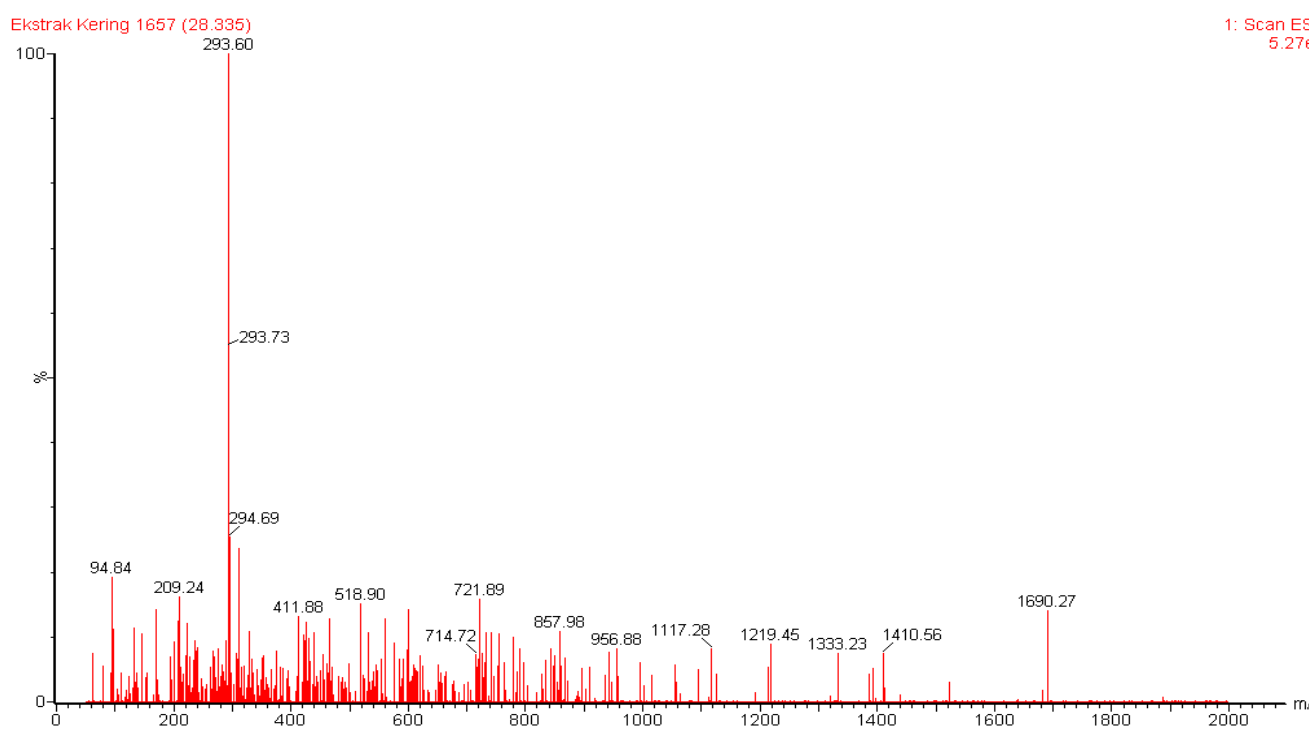

Fig. 2. Results of LC-MS analysis of (a) standard ECG, (b) fresh and (c) dried RSFs extracts analyzed using LC-MS.

Table 2 shows nine chemical compounds found in fresh and dried RSFs extracts. 4H-Pyran4-one, 2,3-dihydro-3,5-dihydroxy-6-methyl- and 2,3-Butanediol, [S-( $\left.\left.\mathrm{R}^{*}, \mathrm{R}^{*}\right)\right]$ - were the highest proportion of chemical compounds (16.72 and $15.54 \%$ ) in the fresh RSFs extracts, followed by D-Glucose, 6-O-à-D-galactopyranosyl- $(12.23 \%)$ while the dried extracts were only glycerine $(27.61 \%)$. Other chemical compounds with both RSFs sections had a proportion of $<10 \%$.

The presence of compounds with pharmacological value was revealed by GC-MS analysis. As a result, fresh and dried RSFs extract yielded a total of 20 compounds. Based on previous studies, glycerine possess antibacterial activity [25]. 4H-Pyran-4-one,2,3-dihydro-3,5dihydroxy-6-methyl- has anti-oxidant, anti-microbial and anti-inflammatory activities [26]. 2,3Butanediol, $\left[\mathrm{S}-\left(\mathrm{R}^{*}, \mathrm{R}^{*}\right)\right]$ - is a vicinal diol and chiral compound that can act as antifreeze agents. As a vital chemical, it can produce important derivatives, such as 1,3-butadiene and methyl ethyl ketone [27]. Honey contains a high level of isomaltose (D-Glucose,6-O-à-D-galactopyranosyl), which when heated could improve immunosuppressive conditions. Heated isomaltose may have a therapeutic role in patients with compromised immunity as a result of chemotherapeutic agents [28]. 
Table 2. Chemical compounds identified in fresh and dried RSFs extracts.

\begin{tabular}{|c|c|c|c|c|c|c|c|c|c|c|}
\hline \multirow[t]{2}{*}{ No } & \multicolumn{2}{|c|}{$\begin{array}{l}\text { Retention Time } \\
\text { (min) }\end{array}$} & \multicolumn{2}{|c|}{$\begin{array}{l}\text { Peak Height } \\
\text { (mAU) }\end{array}$} & \multicolumn{2}{|c|}{$\begin{array}{l}\text { Area } \\
(\%)\end{array}$} & \multirow[t]{2}{*}{ Nomenclature } & \multirow[t]{2}{*}{ Formula } & \multirow[t]{2}{*}{ M.W. } & \multirow[t]{2}{*}{ Activity } \\
\hline & Fresh & Dried & Fresh & Dried & Fresh & Dried & & & & \\
\hline 1 & 4.18 & 4.26 & $160,932,511.21$ & $164,595,000.46$ & 15.54 & 4.59 & $\begin{array}{l}\text { 2,3-Butanediol, } \\
\left.\left(\mathrm{R}^{*}, \mathrm{R}^{*}\right)\right]-\end{array}$ & $\mathrm{C} 4 \mathrm{H} 10 \mathrm{O} 2$ & 90 & Antifreeze agents \\
\hline 2 & 6.84 & 7.55 & $8,876,450.23$ & $85,412,847.24$ & 2.41 & 27.61 & Glycerin & $\mathrm{C} 3 \mathrm{H} 8 \mathrm{O} 3$ & 92 & $\begin{array}{l}\text { Antibacterial, as a } \\
\text { moisturizer for } \\
\text { rough, dry, itchy, } \\
\text { scaly and irritated } \\
\text { skin (e.g., skin } \\
\text { burns from } \\
\text { radiation therapy, } \\
\text { diaper rash) }\end{array}$ \\
\hline 3 & 10.12 & 10.12 & $144,688,126.82$ & $234,968,483.55$ & 16.72 & 8.19 & $\begin{array}{l}\text { 4H-Pyran-4-one,2,3- } \\
\text { dihydro-3,5-dihydroxy- } \\
\text { 6-methyl- }\end{array}$ & $\mathrm{C} 6 \mathrm{H} 8 \mathrm{O} 4$ & 144 & $\begin{array}{l}\text { Antimicrobial, } \\
\text { anti- } \\
\text { inflammatory, } \\
\text { antioxidant } \\
\text { activity }\end{array}$ \\
\hline 4 & 11.15 & 11.14 & $29,379,407.98$ & $149,812,870.81$ & 3.73 & 5.78 & $\begin{array}{l}\text { 5- } \\
\text { Hydroxymethylfurfural }\end{array}$ & C6H6O3 & 126 & $\begin{array}{l}\text { Antiproliferative } \\
\text { inhibits the } \\
\text { formation of } \\
\text { sickled cells in the } \\
\text { blood, active } \\
\text { natural ingredient } \\
\text { in nutraceuticals } \\
\text { and dietary foods }\end{array}$ \\
\hline 5 & 11.69 & 12.13 & $29,549,604.02$ & $8,576,113.84$ & 12.23 & 0.77 & $\begin{array}{l}\text { D-Glucose,6-O-à-D- } \\
\text { galactopyranosyl- }\end{array}$ & $\mathrm{C} 12 \mathrm{H} 22 \mathrm{O} 11$ & 342 & $\begin{array}{l}\text { Melibiose, the } \\
\text { reduction of the } \\
\text { intracellular } \\
\text { concentration of } \\
\text { toxic sugars or } \\
\text { sugar metabolites }\end{array}$ \\
\hline 6 & 13.09 & 13.28 & $21,790,168.80$ & $37,786,571.98$ & 7.05 & 4.64 & Sucrose & $\mathrm{C} 12 \mathrm{H} 22 \mathrm{O} 11$ & 342 & Source of energy \\
\hline
\end{tabular}




\begin{tabular}{|c|c|c|c|c|c|c|c|c|c|c|}
\hline 7 & 14.96 & & $11,219,522.35$ & & 3.78 & & $\begin{array}{l}\text { Cyclooctasiloxane, } \\
\text { hexadecamethyl- }\end{array}$ & $\mathrm{C} 16 \mathrm{H} 48 \mathrm{O} 8 \mathrm{Si} 8$ & 592 & Antimicrobial \\
\hline 8 & 19.01 & 19.01 & $16,318,537.00$ & $79,936,279.59$ & 2.24 & 3.74 & n-Hexadecanoic acid & $\mathrm{C} 16 \mathrm{H} 32 \mathrm{O} 2$ & 256 & $\begin{array}{l}\text { Palmitic acid, } \\
\text { antiviral, anti- } \\
\text { inflammatory, } \\
\text { antibacterial, } \\
\text { antimicrobial, } \\
\text { hypocholesterole } \\
\text { mic, nematicide, } \\
\text { pesticide, } \\
\text { hemolytic, } \\
\text { lubricant, 5- } \alpha- \\
\text { reductase inhibitor }\end{array}$ \\
\hline 9 & & 13.13 & & $78,414,479.65$ & - & 7.32 & $\begin{array}{l}\text { 4H-Pyran-4-one,5- } \\
\text { hydroxy-2- } \\
\text { (hydroxymethyl)- }\end{array}$ & C6H6O4 & 142 & $\begin{array}{l}\text { Kojic acid, } \\
\text { catechol oxidase } \\
\text { inhibitor, } \\
\text { antibiotic, } \\
\text { antioxidant, skin } \\
\text { lightening agent }\end{array}$ \\
\hline
\end{tabular}




\subsection{Quantification of ECG Compound}

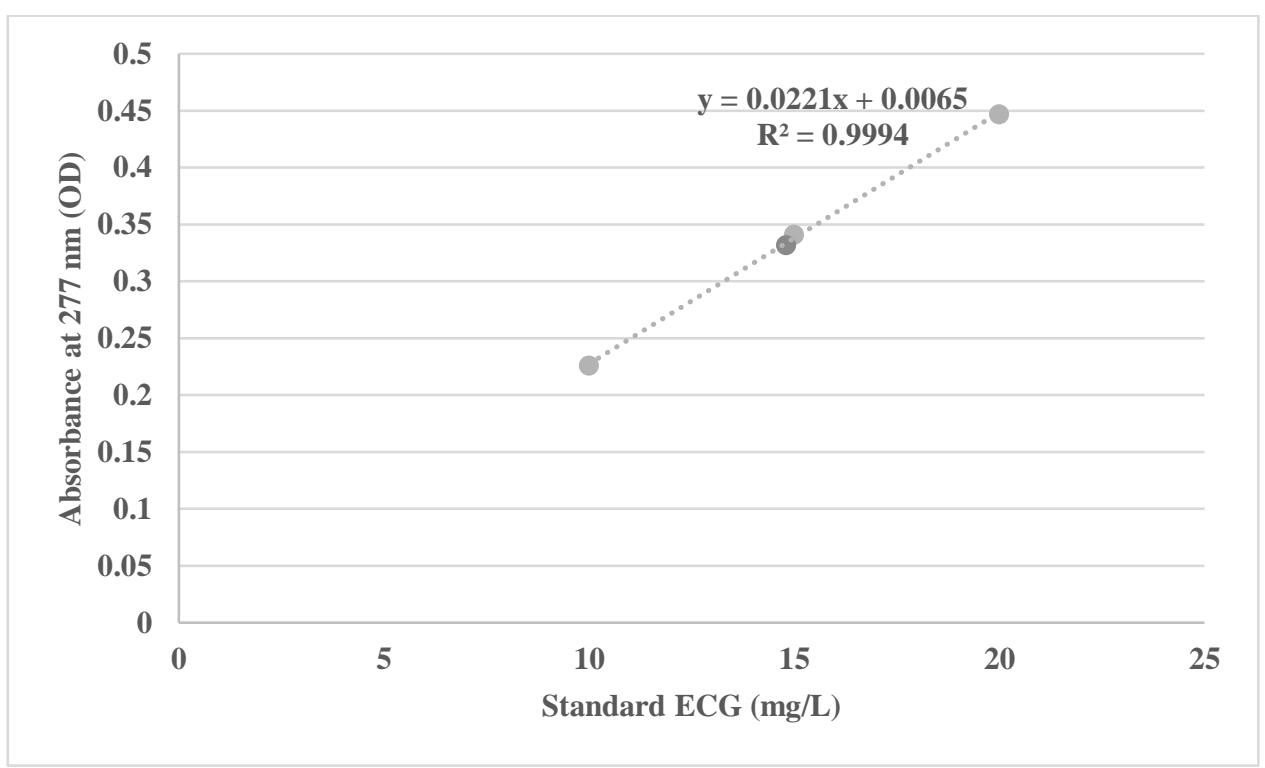

Fig. 3. A standard curve of standard ECG measured using a spectrophotometer at $277 \mathrm{~nm}$.

Table 3. Quantification of ECG compound in fresh and dried RSFs extracts.

\begin{tabular}{lccr}
\hline & Extract concentration $\left(\mathrm{mg} \mathrm{L}^{-1}\right)$ & ECG concentration $\left(\mathrm{mg} \mathrm{L}^{-1}\right)$ & $p$ \\
\hline Fresh & 100 & $1.65 \pm 0.25$ & \\
Dried & 100 & $6.2 \pm 0.6$ & 0.002 \\
\hline
\end{tabular}

The mean data are presented \pm S.D. Significant differences between fresh and dried samples were determined using an independent t-test. $P$-value indicates a substantial difference.

Further analysis using a spectrophotometer was used to quantify the ECG concentration in fresh and dried RSFs extracts [Figure 3 and Table 3]. A linear regression formula $\mathrm{y}=0.0221 \mathrm{x}+$ 0.0065 , generated using some diluted standard ECGs, was needed to calculate ECG concentration in both extracts. Fresh and dried RSFs extracts had $1.65 \pm 0.25 \%$ and $6.2 \pm 0.6$ $\%$ ECG concentrations. Statistically, the ECG concentration in dried RSFs extracts was significantly higher than the ECG concentration in fresh RSFs extracts with $\mathrm{P}=0.002$. Based on the authors' knowledge, we firstly reported the ECG concentration in fresh and dried RSFs extracts. By water removal in the dried RSFs extract, the ECG concentration increases 3.76 times higher than fresh RSFs extract. Another reason for increased ECG concentration in dried RSFs extracts is that the ECG compound has thermal stability during the drying process [29]. 


\section{Conclusion}

Extraction of fresh RSFs has a greater yield than the extraction of dried RSFs. However, ECG compound is detected in dried RSFs extract, consisting of different phytochemicals from fresh RSFs extract. In addition, the dried RSFs section has a $6.2 \pm 0.6 \mathrm{mg} / \mathrm{L} \mathrm{ECG} \mathrm{compound,}$ which is more significant than the fresh RSFs extract $(1.65 \pm 0.25 \mathrm{mg} / \mathrm{L})$. Therefore, it becomes a potential herbal drug for diabetes patients against the high expression of SGLT2 protein.

Acknowledgments. We want to thank the Department of Pharmacology and Therapy staff, Faculty of Medicine, Public Health and Nursing, Gadjah Mada University, Yogyakarta, for making RSFs extracts. Department of Chemistry, Faculty of Mathematics and Natural Sciences, Sriwijaya University for GC-MS analysis. Integrated Laboratory of Mathematics and Natural Sciences, Universitas Sebelas Maret, Surakarta for HPLC-MS analysis. Technical Implementation Unit of Integrated Laboratory, Universitas Sebelas Maret, Surakarta for UVvisible spectrophotometer analysis.

\section{References}

[1] World Health Organization. Diabetes. Geneva: WHO Press; 2020.

[2] International Diabetes Federation. IDF Diabetes Atlas. Ninth edit. Brussels: International Diabetes Federation; 2019. 168 p.

[3] McGrowder DA, Miller FG, Nwokocha C, Wilson-Clarke CF, Anderson M, Anderson-Jackson L, Williams L, Alexander-Lindo R. Treating Endocrine and Metabolic Disorders With Herbal Medicines. Pennsylvania: IGI Global; 2021. Chapter 3, Medical Herbs and the Treatment of Diabetes Mellitus: Mechanisms of Action; 48-73 p.

[4] Pereira MJ, Eriksson JW. Emerging Role of SGLT-2 Inhibitors for the Treatment of Obesity. Drugs. 2019;79(3):219-30

[5] Whaley JM, Tirmenstein M, Reilly TP, Poucher SM, Saye J, Parikh S, List JF. Targeting the kidney and glucose excretion with dapagliflozin: Preclinical and clinical evidence for SGLT2 inhibition as a new option for treatment of type 2 diabetes mellitus. Diabetes, Metab Syndr Obes Targets Ther. 2012;5:135-48.

[6] Madaan T, Akhtar M, Najmi AK. Sodium glucose CoTransporter 2 (SGLT2) inhibitors: Current status and future perspective. Eur J Pharm Sci. 2016;93:244-52.

[7] Neumiller JJ, White JR, Campbell RK. Sodium-glucose co-transport inhibitors: Progress and therapeutic potential in type 2 diabetes mellitus. Drugs. 2010;70(4):377-85.

[8] Bolinder J, Ljunggren Ö, Kullberg J, Johansson L, Wilding J, Langkilde AM, Sugg J, Parikh S. Effects of dapagliflozin on body weight, total fat mass, and regional adipose tissue distribution in patients with type 2 diabetes mellitus with inadequate glycemic control on metformin. J Clin Endocrinol Metab. 2012;97(3):1020-31.

[9] Perry RJ, Rabin-Court A, Song JD, Cardone RL, Wang Y, Kibbey RG, Shulman GI. Dehydration and insulinopenia are necessary and sufficient for euglycemic ketoacidosis in SGLT2 inhibitortreated rats. Nat Commun. 2019;10(548):1-10.

[10] Rezkia RA. Penambatan Molekuler: Eksplorasi Inhibitor Sodium Glucose Co-Transporter 2 dari Senyawa Tanaman Herbal Indonesia sebagai Terapi Diabetes Melitus Tipe 2. Surakarta: Universitas Sebelas Maret Library; 2015. 48 p.

[11] Geurts L, Neyrinck AM, Delzenne NM, Knauf C, Cani PD. Gut microbiota controls adipose tissue expansion, gut barrier and glucose metabolism: Novel insights into molecular targets and interventions using prebiotics. Benef Microbes. 2014;5(1):3-17.

[12] Kallithraka S, Garcia-Viguera C, Bridle P, Bakker J. Survey of solvents for the extraction of grape seed phenolics. Phytochem Anal. 1995;6(5):265-7. 
[13] Ruvini L, Dissanayaka W, Chathuni J, Rizliya V, Swarna W, Barana C. Effect of Different Drying Methods on Antioxidant Activity of Star Fruits ( Averrhoa Carambola L .). J Nutr Diet Suppl. 2017;1(1):1-6.

[14] Pang D, You L, Zhou L, Li T, Zheng B, Liu RH. Averrhoa carambola free phenolic extract ameliorates nonalcoholic hepatic steatosis by modulating mircoRNA-34a, mircoRNA-33 and AMPK pathways in leptin receptor-deficient db/db mice. Food Funct. 2017;8(12):4496-507.

[15] Zaiter A, Becker L, Karam MC, Dicko A. Effect of particle size on antioxidant activity and catechin content of green tea powders. J Food Sci Technol. 2016;53(4):2025-32.

[16] Galanakis CM. Functionality of food components and emerging technologies. Foods. 2021;10(1):26.

[17] Leivas CL, Iacomini M, Cordeiro LMC. Pectic type II arabinogalactans from starfruit (Averrhoa carambola L.). Food Chem. 2016;199:252-7.

[18] Pothasak Y, Singhatong S, Natakankitkul S, Dechsupa N, Wanachantararak P, Dechthummarong C, Leelarungrayub J. Active compounds, free radicals scavenging and tumor-necrosis factor (TNF- $\alpha$ ) inhibitory activities of star fruit-sweet type (Averrhoa carambola L.) in vitro. J Assoc Med. 2020;51(1):32-7.

[19] Yang Y, Jia X, Xie H, Wei X. Dihydrochalcone C-glycosides from Averrhoa carambola leaves. Phytochemistry. 2020;174(112364):1-8.

[20] Ramadan NS, El-Sayed NH, Ludger A. Wessjohann, Andrei Mocan, Vodnar DC, Ehrlich A, ElToumy SA, Mohamed DA, Aziz ZA, Farag MA. Nutrient and Sensory Metabolites Profiling of Averrhoa Carambola L. (Starfruit) in the Context of Its Origin and Ripening Stage by GC/MS and Chemometric Analysis. Molecules. 2020;25(10):27.

[21] Verma S, Dhaneshwar S, Ramana MV, Rawat AKS. Gas chromatography-mass spectrometry and high-performance thin-layer chromatography quantifications of some physiologically active secondary metabolites in averrhoa carambola L. fruits. J Planar Chromatogr - Mod TLC. 2018;31(3):207-12.

[22] Soledispa PA, González J, Cuéllar A. Characterization of Catechins from Smilax domingensis Willd . in Cuba. World News Nat Sci. 2019;23:297-305.

[23] MassBank of North America. LC-MS / MS Spectrum - Linear Ion Trap , positive ( HMDB0037944 ). California: MoNA Library

[24] Kohri T, Suzuki M, Nanjo F. Identification of metabolites of (-)-epicatechin gallate and their metabolic fate in the rat. J Agric Food Chem. 2003;51(18):5561-6.

[25] Maria KK, Joanna GK, Katerina AD, Leland GK. Chemical composition and antibacterial activity against Escherichia coli of extracts of a common household plant. J Med Plants Res. 2021;15(1):5663.

[26] Karabonde A, Atiku M, Wudil A, Buratai L. Antioxidant effect of Citrullus vulgaris (watermelon) extract against lipid oxidation in fish during cooking. Bayero J Pure Appl Sci. 2015;7(2):105.

[27] Li L, Wang Y, Zhang L, Ma C, Wang A, Tao F, Xu P. Biocatalytic production of (2S,3S)-2,3butanediol from diacetyl using whole cells of engineered Escherichia coli. Bioresour Technol. 2012;115:111-6.

[28] Xu X, Asai K, Kato D, Ishiuchi K, Ding K, Tabuchi Y, Ota M, Makino T. Honey isomaltose contributes to the induction of granulocyte-colony stimulating factor (G-CSF) secretion in the intestinal epithelial cells following honey heating. Sci Rep. 2020;10(1):1-14.

[29] Su YL, Leung LK, Huang Y, Chen ZY. Stability of tea theaflavins and catechins. Food Chem. 2003;83(2):189-95. 